\title{
La jurisdicción y su término de la ciudad de Toledo en el siglo XVIII
}

\author{
laura Santolaya Heredero *
}

Era de realengo el estricto término de la ciudad. En la respuesta tercera al Interrogatorio general del Catastro de Ensenada ${ }^{1}$ se decía que el mismo tenía tres leguas y cuarto de Levante a Poniente y una y media de Norte a Sur. Confrontaba por Levante con el término y villa despoblada de Higares y el despoblado de Calabazas; por Poniente con el término de Guadamur, dehesa de Daramazas y despoblado de Estibiel; por el Norte con el despoblado de Darrayel Alto y el término de Bargas. Y por el Sur con los términos de Burguillos, Cobisa y Argés.

Las Relaciones particulares del Catastro dan un conjunto, sin la ciudad, de 24.954,10 fanegas $^{2}$ o 11.752 ha., estando divididas en 455 parcelas.

Toledo había tenido un extenso alfoz en la Edad Media a raíz de la reconquista. Quizás porque, como señaló Moxó, la política regia de Alfonso VIII "trató de impedir conscientemente la formación de grandes señoríos nobiliarios en el reino de Toledo, al percibir el peligro que suponía el rápido auge y engrandecimiento que la nobleza castellana estaba experimentando en el siglo $x \mid 1{ }^{3}$.

* UNED

Archivo Provincial de Toledo, en adelante APT, libro 680.

Son fanegas de 500 estadales. Una ha. es igual a 2,1234 fanegas.

3 S. Moxo: Los antiguos señorios de Toledo, Toledo 1973. En pp. 17-18 y 249. 
Dado el alfoz por el rey mediante privilegio o fuero, incluía lugares poblados dependientes jurisdiccionalmente de la ciudad y facultaba a ésta la posibilidad de crear otros nuevos.

A finales de la Edad Media se fue produciendo una partición del mismo en la medida en que los núcleos de población fueron reclamando un espacio territorial y el derecho a administrarse por sí. A la ciudad tales solicitudes la favorecian porque se liberaba de determinados compromisos mientras seguia ejerciendo un práctico control.

En el siglo XVIII, Toledo ejercia su jurisdicción de realengo tan sólo sobre cinco lugares, llamados también por el Catastro lugares-arrabales, en los que nombraba un regidor. Eran Argés, Burguillos, Cobisa, Chueca y Nambroca.

Del término de realengo fueron desgajándose jurisdiccionalmente también los "despoblados". Este vocablo, tal como se utiliza en el Catastro, hacía referencia a no-población, en contraste con los términos poblados, y sobre todo a distinta jurisdicción, independientemente de que tiempo atrás hubiera estado o no poblado. Eran acotamientos privilegiados otorgados por el rey $o$, en segunda instancia, por quien tenia poder de concederlo por ser señor del término: el Ayuntamiento de Toledo, la Dignidad Arzobispal (alfoces de Talavera y Alcalá de Henares) y la Orden de Santiago (Ocaña).

Desde el punto de vista económico muchos figuraban como dehesas, una tierra extensa acotada con un solo producto anual, aunque también aparecen en la fuente despoblados subdivididos en dehesas o "despoblados-dehesas" subdivididos en parcelas.

En el siglo XVIII, el partido de Toledo -que había sido el inicial alfoz de la ciudad - tenía 102 despoblados, con distinta jurisdicción, resultado de concesiones y compras que estaban inscritos en los términos municipales de los lugares poblados que, en su día, se habian independizado de aquélla.

El mismo término de Toledo también tenía "despoblados", lo cual da una idea de lo que en la práctica significaba la complejidad jurisdiccional del Antiguo Régimen. Estaban en él: Calabazas cuyo titular era el marqués de Malpica, Estibiel de la Mariscala de Castilla, La Fuente de la duquesa del Infantado - todos de señorío secular-y Darrayel que pertenecía al Ayuntamiento de la ciudad como señor del mismo. Este último 
resultaba todo un paradigma de jurisdicción porque no era de la ciudad, propiamente tal, sino de su Ayuntamiento.

Hay que añadir, además, otros que estaban en el término de los lugares-arrabales cuya jurisdicción, como se ha dicho, era de realengo de la ciudad: Torre Cervatos, en Argés, pertenecia al Deán y Cabildo Catedral; Montalbanejos, en Nambroca, al Cabildo Catedral (ambos de señorío eclesiástico secular); Palomilla, en Argés, a las monjas de Santa Isabel (señorío eclesiástico regular) y Diezma, en Nambroca, a D. Antonio de Castro, vecino de Granada (señorio secular).

En conjunto, Toledo ejercía la jurisdicción directa de realengo sobre $44.060,5$ fanegas o $20.749,93$ ha. (19.109,7 fan. de los lugares-arrabales) de las que habría que descontar las de los despoblados citados ${ }^{4}$.

Para los historiadores, interesados por el fenómeno jurisidiccional, resulta de mayor relevancia el "señorio concejil" que la ciudad tenía sobre los Montes de Toledo. Este término de «señorío concejil» lo defiende Donézar sustentando en el Interrogatorio General donde se dice que tenía

«... el señorío, dominio y vasallaje de los Montes que llaman de Toledo (...) con todos sus términos, castillos, sitios yermos, despoblados, yerbas, fuentes, ríos, montes, dehesas, aguas, pasturas y otros aprovechamientos, con lo demás que se comprende en el recinto y confines de dichos Montes» ${ }^{5}$.

Geográficamente, ocupaba una amplia zona situada al sur de la provincia denominada "montes de Toledo", "tierra de Toledo" o "propios de Toledo». Tal territorio comprendía dieciséis pueblos situados en las actuales provincias de Toledo y Ciudad Real: Hontanar, Marjaliza, Navahermosa, Navalmoral de Toledo, Navalucillos de Toledo, San Pablo de los Montes, Ventas con Peña Aguilera, Yébenes de Toledo, Alcoba Arroba, Horcajo de los Montes, El Molinillo, Navalpino, Navas de Estena y Retuerta de Bullaque.

${ }^{4}$ APT, libros 703 Calabazas; Estibiel 704; La Fuente 707; Darrayel 704; Torre Cervatos 702; Montalbanejos 708; Palomilla 710; Diezma 704.

${ }_{5}$ APT, libro 716 en Javier DonÉzAR: Riqueza y propiedad en la Castilla del Antiguo Régimen. La provincia de Toledo del siglo XVIII. Madrid 1984, p. 72. 
De modo concreto, y por cuanto a la tierra se refiere, tales núcleos de población - todos ellos lugares- tenian una extensión, según las Respuestas particulares, de 245.166 fanegas de 500 estadales (115.459,56 ha.) con un producto bruto de 1.148 .212 rs. en 8.660 parcelas ${ }^{6}$.

\begin{tabular}{lrcc}
\hline \multicolumn{1}{c}{ PUEBLOS } & PROOUCTO & FANEGAS & PARCELAS \\
\hline Hontanar & 16.864 & $18.408,6$ & 158 \\
Marjaliza & 149.952 & $3.932,11$ & 715 \\
Navahermosa & 106.724 & $27.266,2$ & 1.053 \\
Navalmoral Toledo & 299.889 & $4.239,4$ & 793 \\
Navalucillos Toledo & 93.988 & $1.652,4$ & 572 \\
San Pablo & 33.302 & $2.914,3$ & 1.126 \\
Ventas con Peña Aguilera & 242.636 & $14.126,9$ & 1.323 \\
Yébenes Toledo & 96.660 & $4.154,11$ & 675 \\
Alcoba & 22.483 & 975,11 & 165 \\
Arroba & 16.381 & $25.715,6$ & 659 \\
Horcajo de los Montes & 29.236 & $12.985,8$ & 608 \\
El Molinillo & 16.257 & $112.935,2$ & 73 \\
Navalpino & 16.109 & $14.871,1$ & 501 \\
Navas de Estena & 2.072 & 162,3 & 26 \\
La Retuerta & 5.659 & 826,1 & 213 \\
\hline \multicolumn{1}{c}{ TOTAL } & 1.148 .212 & $245.166,10$ & 8.660 \\
\hline
\end{tabular}

${ }^{6}$ APT, Hontanar 316; Marjaliza 372; Navahermosa 422; Navalmoral Toledo 434 y 436 ; Navalucillos Toledo 438; San Pablo 598; Ventas con Peña Aguilera 805; Yébenes Toledo 879; Alcoba 640 del Arch. ${ }^{\circ}$ Prov. Ciudad Real; Arroba 660 de Idem; Navalpino 721 de Idem; Navas de Estena 721 de ldem; Horcajo de los Montes 319 de APT; El Molinillo 400 de Idem; La Retuerta 572 de Idem. 
Del total de la extensión formaban los propios de la ciudad 203.315 fan. (82,9 por 100) que las arrendaba a grandes ganaderos o a la Mesta para sostener el Pósito y hacer frente a los gastos municipales.

De ellas, 197.496 fan. se dividian en tan sólo seis parcelas ${ }^{7}$ por lo que la ciudad se convertía en la máxima latifundista de la provincia, teniendo, además, otras cinco parcelas con un total de 5.819 fanegas. Hay que destacar, sobre todo, una parcela en El Molinillo de 110.751 fan. y dos que hacian 1.860 fan.

Por lo que la propiedad particular, incluido el Estado eclesiástico -aunque éste no sea "particular"-, se limitaba a 41.851,10 fanegas distribuida en pequeñas parcelas de baja calidad cuya extensión media era de 4,10 fan.

Una Memoria redactada en 1821 y presentada a las Cortes del Trienio, que utilizaremos, decía que los Montes tenían

«... una escasísima y pobrísima población (...) Los pocos colonos que los habitan, agobiados, menos por las grandes cargas que pagan a Toledo, que por la mala administración y por la arbitrariedad y despotismo del juzgado y guardas de estos Montes, gimen en la miseria y abandono, procurando únicamente sacar de la tierra lo preciso para sustentarse" ${ }^{8}$.

Si se considera qué resultaba en números tal población y quiénes se dedicaban por oficio a la agricultura, se tiene que estaba compuesta por 10.506 individuos del Estado seglar y 66 del eclesiástico; solamente tres pueblos superaban el millar de habitantes que hacian el 52,4 por 100 del total (Yébenes de Toledo 2.433, Navahermosa 1.862 y Navalucillos de Toledo 1.213).

Eran labradores 461 vecinos y jornaleros 1.455. La mayor parte dependía de otro, del salario de otro, para poder subsistir. $Y$ si se interpreta

${ }^{7}$ Se considera como "parcela" la unidad de extensión que tiene un solo producto ante el Catastro. En este sentido, tanto da la parcela de media fanega como la de cinco mil.

${ }^{8}$ Memoria, sobre la pertenencia extensión, calidad de tierras, población y administración de los Montes de Toledo por el Ayuntamiento de esta ciudad, y sobre el sistema que deberá adoptarse en su repartición y enajenación; presentada a las Cortes generales por Julián Antonio López y Francisco Martínez Robres. Madrid 1821. En p. 3. 
que eran «labradores" aquellos que tenian tierras y pagaban por ellas al fisco por ser residentes, todavía habría que disminuir su posibilidad de lograr excedentes porque 10.606,3 fan. eran de propietarios forasteros en 1.467 parcelas.

Así que quedaban a los vecinos residentes $31.245,7$ fan. en 7.182 parcelas y 745.427 rs. de producto. La media de producto por parcela era de 103,27 rs., a todas luces insuficiente para obtener un ahorro que mejorara las condiciones de vida, con una calidad de la tierra baja porque entre las cincuenta clases que establecieron los comisionados del Catastro para la provincia estaría situada entre la clase 42 y 43 .

Basten estos datos, referidos exclusivamente a la extensión de la tierra, para centrar la cuestión de la administración resultante de la jurisdicción.

Tenía la ciudad para el gobierno de esta extensión un juzgado en Toledo, llamado de "los Montes", que estaba compuesto por un fiel del juzgado -era un regidor que se elegía cada cierto tiempo por suerte entre la totalidad de los regidores - y un tribunal que trataba de la administración y fallaba en los casos gubernativos y contenciosos que podian presentarse.

El Ayuntamiento de Toledo tenía el derecho de nombrar los alcaldes de los pueblos entre una terna que éstos presentaban.

La Memoria citada criticaba la situación general y el general abandono:

“... cada pueblo de los Montes tiene su término llamado diezmería por haberse formado principalmente por la formación de los diezmos; en cuyo término o diezmeria tiene cada uno acotada una porcion de tierra con el título de dehesa boyar, que la disfrutan por sí solos sus ganados. Debe exceptuarse Hontanar que no disfruta dehesa, acaso por no haber hecho méritos para que le concediesen esta gracia los señores de los Montes" ".

${ }^{9}$ Memoria..., p. 30. 
A los pueblos situados dentro de los Montes únicamente se les permitía labrar en las rozas, esto era, en porciones de terreno que anualmente se señalaba

«... precediendo súplicas, reconocimientos y despachos ante el juez del juzgado, ascendiendo cada año los derechos de todo esto a muy buenas sumas. El señalamiento lo hace uno de los cuatro guardas que hay de montes, verificándolo siempre en los peores terrenos, bajo el pretexto de no tocar a lo demás para que se crie buen monte. El terreno señalado lo reparten entre si los vecinos de cada pueblo y como deban pasarse muchos años antes que vuelva a rozarse la misma tierra, y no tengan por consiguiente interés alguno en desceparla y laborearla bien, el único cultivo que le dan consiste en rozar los arbustos y matas en la primavera, reunir lo rozado en montones que pegan fuego a fin de agosto, ocasionándose no pocas veces considerables daños, a causa de propagarse el fuego, con el más mínimo descuido, leguas enteras. Extendiendo después la ceniza, sin más preparación, esparcen la semilla a voleo, abandonando ya el sembrado hasta la época de segar, en la que recogen lo que pudo germinar buenamente y no destruyeron los insectos y demás animales campesinos. Algunos para cubrir un poco la semilla suelen rastrear la superficie con rastros de mano, o bien introducen manadas de cabras que medio la entierran, haciéndolas pasar por cima apiñadas y de tropel.

Estos miserables labradores nos recuerdan los primeros tiempos de la formación de las sociedades, en cuya época no se servian los hombres de los animales para labrar la tierra, ni se había inventado aún el primero de los instrumentos campestres, el arado..." ${ }^{10}$.

Los pueblos del exterior, aquellos que bordeaban los Montes, tenían, sin embargo, una superior riqueza, algo de industria, a pesar de que sobre todos - del interior y exterior- recaía como máxima expresión del dominio de la ciudad el impuesto del dozavo sobre todos los frutos de la tierra, colmenares y ganados. Habian sabido romper el terreno para sembrar:

“... estimulado así el interés individual han sabido establecer en los terrenos más infimos viñedos, olivares y aun preciosos jardines. Para romper terrenos y no labrar en rozas no han tenido otros méritos que el ser más ricos, haber tenido favor, haber sido más sagaces o más atrevidos" ".

${ }^{10}$ Memoria..., pp. 30-32.

"Ibidem, p. 34. 
En conjunto, la ciudad no llevaba bien la administración. Las quejas se habían sucedido durante el siglo XVIII y la Memoria de 1821 las resumía: a pesar de ser extensos los terrenos para pastos comunes, eran pocos los ganados que se asentaban en ellos.

“Nada diremos del disfrute de la bellota pues en el abandono actual del arbolado, siendo el usufructo de ella de mancomún, viene a reducirse su esquilmo casi a la nada. Cada cual que quiere lleva sus cerdos donde se le antoja, y saltando sin cesar de un lado para otro, recogen unos lo que otros abandonan no utilizándose ninguno del fruto de un modo ventajoso: así acontece ser muy poco el ganado que se ceba en estos montes" ${ }^{12}$.

Tampoco la ciudad se beneficiaba del usufructo de la leña y el carbón resultante debiéndose aprovisionar de otros lugares.

Las generales ganancias que parecía debían surgir de la propiedad de tan grande extensión no redundaban en mejoras sociales:

"Al mismo tiempo se observa que no se sostiene por el Ayuntamiento ninguna obra de pública utilidad, ni casa alguna de beneficencia, ni siquiera para una escuela para los pobres; que la limpieza, el alumbrado y casi todo el empedrado de las calles los costean los vecinos; que la Academia de Bellas Artes se mantiene casi de limosna; que la Sociedad Económica no tiene con qué premiar a los industriosos y aplicados; que la agricultura se enseña sólo teórica y no prácticamente por falta de terreno; y por último, que en la Universidad por falta de medios se enseñan algunas ciencias muy inexactas e incompletamente, no teniendo los profesores o sustitutos, que regentan las cátedras, otro aliciente que los estimule a sus tareas que el del honor" ${ }^{13}$.

Es preciso volver al asunto del "señorío concejil" una vez ofrecido un panorama de la realidad existente. Algunos historiadores se han preguntado si este término constituía un auténtico señorío. Su aceptación supondría casi una "revolución", en el panorama institucional. Donézar, como se ha dicho antes, lo defiende. Moxó incluía a los núcleos poblados

12 Ibidem, p. 42.

${ }^{13}$ Memoria..., pp. 44-45. 
que ejercieron sobre otros una cierta forma dominical después de la conquista en la fórmula de "realengo indirecto".

En las Respuestas particulares se repite la expresión de "señorío y jurisdicción de la ciudad" como distinta de "realengo y jurisdicción de la ciudad". En Marjaliza se decía que era "señorío concejil de la ciudad de Toledo" y en San Pablo de los Montes:

«Dijeron que este lugar es propio de la Imperial ciudad de Toledo a quien pertenece su jurisdicción, y como tal señor percibe..." ${ }^{14}$.

Todo ello puede parecer novedoso a primera vista pero es perfectamente válido si se observa que el señorío de la ciudad tenía su origen en una compra hecha al rey con todas las prerrogativas y derechos inherentes.

Por eso, el dozavo, ya citado, expresaba esta dependencia de los pueblos. Reunía distintos derechos señoriales; era una especie de "diezmo" general:

«...sin que por razón del establecimiento del suelo se paguen mrs. algunos a la ciudad de Toledo como dueña que es de él por incluirse todo en el derecho dozavo». Y más adelante: que los pueblos no pagaban censos ni cargas algunas por las tierras y edificaciones porque todo iba en el derecho de dozavo" ${ }^{15}$.

Tal renta «por su costosa administración se arrendaba a particulares" cobrándose de todos los lugares menos de El Molinillo

«...que estaba para despoblarse (...) por gracia que le hizo esta ciudad para que se aumente su población” ${ }^{16}$.

${ }^{14}$ Ibidem, libro 598.

15 Ibidem, libro 689.

${ }^{16}$ Ibidem, libro 716. 
Sin embargo, y pese al dominio eminente sobre la tierra por parte de la ciudad, el servicio ordinario estaba cargado res" " $" 17$

"...sobre los bienes raices que poseen los vecinos de los luga-

La solución al dilema viene dada en la defensa que la ciudad hizo en 1741 sobre su "señorío concejil" porque determina la afirmación del concepto. No sabemos si otras ciudades de Castilla plantearon en algún momento lo mismo o si tuvieron dicho "señorio"; de todos modos, el asunto es indicativo.

El resultado fue la «Real Cédula y título de declaración de la pertenencia y propiedad de los lugares de los Montes de Toledo desta ciudad expedido en favor de su IImo. Ayuntamiento" ${ }^{18}$.

Y el motivo la defensa de D. García Núñez de Haro, abogado de los RR. Consejos y Fiscal de la Corona, por la reintegración al Real Patrimonio de los baldíos y despoblados. Si lo primero tenía una posibilidad, lo segundo era dificil si se interpreta, según se ha descrito, el «despoblado" como un territorio de distinta jurisdicción más que como un término no-poblado.

En su apoyo el abogado introdujo un concepto que no creemos que haya sido, por ahora, objeto de demasiada atención: era el de «baldio fiscal». Comúnmente se ha interpretado el baldío como algo inherente a la tierra: una tierra era baldia si, por lo menos aparentemente, nada estaba produciendo. En su informe decía:

«El Ilmo. Ayuntamiento de esta ciudad goza y detenta diferentes sitios baldíos (...) particularmente el que vulgarmente denominan los montes de Toledo". Y se citaban a continuación los términos municipales que explicaban los "sitios baldíos"".

17 Ibidem, libro 689.

18 A.P.T., libro 695. 
De donde hay que deducir que «baldío" no era utilizado como un concepto económico de producción sino fiscal - lo que no estaba produciendo nada a Hacienda- porque aquel, como tal, comprendía lugares productivos y eso eran los pueblos que se describian.

Más adelante afirmaba en dicho informe:

"...en lo que está de mi parte desde luego denuncio por tales baldíos fiscales y realengos los referidos términos llamados los Montes de Toledo con todo lo que incluyen...".

Sin prentender hacer exégesis alguna del párrafo conviene señalar por un lado la unión de «baldío» y «realengo» que, a primera vista, podría exultar a los recientes estudiosos sobre la esencia del Real Patrimonio $y$, por otro, que eran productivos según la frase "con todo lo que incluyen" porque, propiamente, no podrían incluir "nada".

La idea de "baldío fiscal» quedaba reforzada cuando se pretendia reintegrarlos a la Corona aceptando que habian producido rentas:

“...así reintegrarse a su posesión y propiedad condenando a este IImo. Ayuntamiento a la restitución de todas las rentas que haya percibido".

Por tanto, para la Corona eran los Montes de Toledo «baidios fiscales" porque de ellos no percibia nada; por ello debian ser reintegrados a la misma lo cual implicaba que tampoco le correspondía a la ciudad percibir sus rentas.

Pero en este punto empezaba la defensa de Toledo. Si en 1741 el problema había sido considerar a los Montes de Toledo como baldios y, por tanto, de la Corona, la respuesta del Ayuntamiento fue mostrar los documentos de propiedad. Una cosa era que fueran «baldíos" para la Corona y otra que no tuvieran propietario.

«Es dueño y señor en posesión y propiedad de todos los montes que llaman de Toledo así yermos como poblados y de todas sus tierras, dehesas, árboles, castillos y lugares y con todas las derechuras y lo 
demás en ellos contenido cuya tierra de dichos montes linda con tierra del Priorato de San Juan (...) (se enumeraban las lindes como muestra de propiedad)".

Presentó, además, una copia auténtica de la carta de venta que el rey D. Fernando III había otorgado el año 1246 en pro de la ciudad, su consejo y vecinos (reconocida ante el juez en 14 de enero de 1741) con los consiguientes privilegios:

«(...) cuya posesión y propiedad tiene ejecutoria esta ciudad por sentencias de vista y revista en cuanto a la posesión, porque habiéndose tratado de vender dichos Montes y puéstose en secuestro la jurisdicción civil y criminal de que usaba y ejercia por su fiel de Juzgado salió la ciudad a la defensa y seguido el pleito en contradictorio juicio con el Sr. Fiscal de S.M. en 29 de febrero de 1640, por auto del Real Consejo se revocó el secuestro puesto en la jurisdicción y se le mandó volver a Toledo...".

Y además otros documentos. El que daba la razón a la ciudad con la explicación del pleito acabado de mencionar y el derivado de una demanda puesta por el Concejo de la Mesta en 18 de julio de 1656

«...pretendiendo ser dichos montes y sus términos de Su Majestad en propiedad junto con su jurisdicción y no tener en ellos Toledo ni en los lugares de ellos jurisdicción, ni otro derecho que el del aprovechamiento común y éste guardando las leyes del reino".

Ganó de nuevo el Ayuntamiento este pleito demostrando que era propietario y señor: "Alegando ser dueño y señor de dichos montes $y$ lugares que estaban en ellos y de su jurisdicción y de todo el suelo y término de dichos montes y castillos de mojón a mojón, y de linde a linde, y de garganta a garganta y de sierra a sierra, fuentes y rios con entradas y salidas...». La sentencia se confirmó en 8 de julio de 1665 «y en virtud de ella ha continuado y continúa esta ciudad en el señorio, propiedad y posesión de dichos montes y su jurisdicción" (de todo ello se daba fe el 16 de diciembre de 1739).

Por ambos documentos no habia 
"...motivo alguno para que dichos montes y términos o algunos de ellos se contemplen baldíos, realengos mediante la legítima y solemne abdicación de la Real Corona».

Finalmente, presentó la carta de otorgamiento:

"Conocida cosa sea a todos los que esta carta vieren cómo yo D. Fernando por la gracia de Dios rey de Castilla y de Toledo, de León y de Galicia, de Córdoba y de Murcia con placer y con otorgamiento de la reina Doña Berenguela mi madre en uno con la reina Doña Juana mi mujer e con mis hijos D. Alfonso, D. Fradrio y D. Enrio, vendo a vos Concejo de Toledo, a los caballeros y al pueblo y a cristianos y a moros y a judíos que sodes y a los que han de ser adelante, todos aquellos términos que el arzobispo D. Rodrigo de Toledo tenía y habia en sus cartas, y todo aquello que él a mí vendió también de compras como de donadios de los reyes, que antes fueron que yo, y lo que él tenía por mio otorgamiento y con todas las tenencias que él tenia, y con todo aquello que él vendió a mi sobredicho rey y con todos los términos que en las cartas del arzobispo dice, de mojón a mojón y de linde a linde, y de garganta a garganta y de sierra a sierra así como es señalado y amojonado en las cartas que el sobredicho arzobispo hubo de donadíos de mis antecesores y de mi y con todo aquello que en la mi carta, porque yo de él compré, dice (...) (se mencionan los lugares) y con todas las derechuras asi como las cartas del arzobispo dicen que yo dí a vos con Montazgos y Portazgos, con herbazgos y con fuentes con ríos, y con montes con dehesas, con aguas y con pasturas, con entradas $y$ con salidas cumplidamente y pleneramiente, $y$ todo esto vos vendo a vos apodero en ello por cuarenta y cinco veces mil morbis Alfonsís que me disteis y otorgo que soy pagado de ellos..."

El argumento de D. Garcia Núñez de Haro para afirmar que los Montes eran de la Corona:

“...y porque es constante que todas las tierras incultas y montes privativamente pertenecen a la Real Hacienda, por lo que siendo de esta naturaleza el territorio que se litiga procede sin la menor controversia la reintegración que llevo perdida".

Pero precisaba más dudando de la jurisdicción: 
«(...) y porque a lo dicho no puede obstar los instrumentos presentados porque el principal en que podía la contraria afianzar su pretendido derecho que es el que se nombra escritura de venta que otorgó el santo rey D. Fernando al Concejo de Toledo como referente al otorgado por el arzobispo D. Rodrigo a favor de aquella Majestad no se puede extender su adquisición, ni ampliar más su dominio que a los derechos que dicha Dignidad gozó pues no se enuncia vendiese otros, y como quiera que no se sabe, ni se ha demostrado por el Ilmo. Ayuntamiento la cualidad de lo que motivó el señorío de oicho arzobispo, se quedan con otra total indiferencia como que dimana la venta de lo que vendió el arzobispo al santo rey $D$. Fernando. $Y$ porque en estos términos es absolutamente innegable que Su Majestad se está en la posesión de todos los derechos que legitimamente residen en la Corona y últimamente en lo que de los límites adentro resultare vendido, inculto, montuoso y demás en que de derecho funda el Real Patrimonio su intención y necesita el poseedor de legítimo título para su goce, en cuyo supuesto no teniendo la parte del I/mo. Ayuntamiento otro que la mencionada escritura y ésta no declara qué derechos son los que vende, siendo los que tuvo del arzobispo $\mathrm{D}$. Rodrigo únicamente, se hace evidentemente preciso la reintegración que pido ofreciéndome desde luego (siendo necesario) a justificar la entidad de todos, por tanto (...) a V.M. suplico..." (11 de abril de 1741).

Si la jurisdicción era del rey y no de Toledo, los baldíos podian incorporarse a la Corona.

En 1243 se había producido un trueque en favor de Jiménez de Rada de ciertas villas y lugares a cambio de los lugares poblados, yermos y demás términos que se comprendían en los Montes de Toledo.

Daba el rey Fernando al arzobispo y sus sucesores la

«...villa e el mio cellero que dicen Annoel con su castillo que es en ribera del Tajo con vasallos (...) e con todas sus derechuras et do vos demás aquella villa que dicen Bazta (Baza) que es agora en poder de los moros...".

Le ofrecía esta villa para que se comprometiera a conquistarla, y el rey añadía: "y si por ventura ganar no la pudiésedes, yo no sea tenudo otra ayuda vos facer» y ni él ni el Cabildo ni sucesores podrían pretender a cambio otra cosa por no poder conquistarla. 
Lo importante es señalar que la ciudad de Toledo sustentaba su derecho en haber realizado una compra "total», esto era, habia comprado «todo»: tierra y jurisdicción.

Por otra parte, su defensa estaba en mostrar cómo había sido el trueque entre el rey y el arzobispo para luego aducir que habia comprado "todo" 10 del rey.

El rey en su cambio con el arzobispo había retenido en Bazta lo siguiente:

«...que en Bazta y en todos sus castillos y en todas sus aldeas y en todos sus términos retengo para mi que hagan guerra y paz cuando yo mandare y retengo para mí conducho y todos los otros derechos que el rey ha en las otras villas que son heredad de Santa María de Toledo. Otrosí retengo para mi cuando yo fuere a Bazta personalmente que haga justicia como rey...".

Y en Annoel:

«...todas las derechuras que rey ha en las otras villas que son heredad de Santa María de Toledo (...)".

"Et por todas estas cocas que vos yo do recibo de vos en cambio..." y se mencionaban los mismos lugares que el rey luego citaría en su venta a la ciudad.

El rey había recibido las extensiones con todos sus derechos y asi las pasó a la ciudad "sin retener nada para sí».

Por eso Manuel Bravo, abogado del Ayuntamiento, respondió al fiscal Núñez de Haro:

«...y porque el dominio propiedad y pertenencia que tiene y le compete al limo. Ayuntamiento, mi parte, de los referidos montes, sus términos, sitios y poblados con todos los demás aprovechamientos que se comprehenden en su distrito es tan indubitable y notorio que no admite 
controversia ni disputa alguna por fundarse mi parte en la venta que de todo se le hizo por el Sr. Rey D. Fernando en la era...".

Ai final, el licenciado D. Juan Royo Gabaldón, abogado de los RR. Consejos y Juez Subdelegado de tierras baldías, realengas, despoblados y arbitrios de Toledo y su partido, declaró que

"...habiendo visto los autos seguidos entre el Promotor fiscal de su Audiencia en nombre de S.M. y su Real Patrimonio y el Ilmo. Ayuntamiento que (...) pertenece todo a dicho Ilmo. Ayuntamiento en posesión y propiedad mediante el pleno dominio, señorio y vasallaje que tiene y le compete en virtud de dichos $R$. Privilegios y Títulos. $Y$ en consecuencia no estar comprehendido en el R. Decreto de Su Majestad expedido para la reintegración de baldios y tierras realengas a la Corona...".

Este D. Juan Royo mandó que se hiciera consulta a los Señores de la Real Junta de Baldíos con remisión de los autos originales (25 mayo 1741). Pero como el rey suprimió dicha Junta de Baldíos el día 5 de junio, la ciudad de Toledo siguió el proceso ante el Consejo de S.M. y lo presentó el 3 de agosto de 1742.

D. Miguel Fernández Munilla, secretario escribano de Cámara y Gobierno, dictó un certificado por el que constaba haber recibido la petición «para ponerla en su archivo de Cámara» (28 junio de 1743).

La ciudad de Toledo volvió con un pedimento suplicando que, pues estaba presentada, se mandara librar la ejecutoria o despacho competente para el resguardo de su dërecho.

Esta se libró a favor de la ciudad el 11 de julio de 1743. 